\title{
Perancangan Ulang Meja Belajar Mahasiswa Menggunakan Metode Rekayasa Nilai Dan Pendekatan Ergonomi
}

\author{
Dian Maya Susiladewi ${ }^{1}$, Muhammad Yusuf ${ }^{2}$, Risma Adelina Simanjuntak ${ }^{3}$, Nur Rahmawati ${ }^{4}$ \\ ${ }_{124}$ Jurusan Teknik Industri, Institut Sains \& Teknologi AKPRIND Yogyakarta \\ ${ }^{3}$ Program Studi Bisnis Digital, Institut Sains \& Teknologi AKPRIND Yogyakarta \\ Email: yusuf@akprind.ac.id
}

\begin{abstract}
Yogyakarta is known as a city of students, many public and private universities. Based on this, students come from several regions to study. The learning process in higher education cannot be separated from facilities that support learning activities such as study tables and laptops. Students use laptops every day for a long time. Most students complain that the study table is not comfortable when used but it also causes students to tire more quickly. Fatigue is felt in the neck, back, legs and hands. Therefore, it is necessary to redesign the student desk to make it more ergonomic. The method used in redesigning student desks is value engineering. Function identification is performed using FAST diagrams. From the results of the identification of needs and functions, it is necessary to repair and redesign student desks. So from this study, the results of the student study table design with the addition of parts to be able to adjust the height and slope of the laptop, a place for glasses and cables, an adjustable study table height and also a footrest. Then the size of each table is adjusted to the dimensions of the Indonesian anthropometric body, the final result of this research is a more ergonomic student desk design.
\end{abstract}

Keywords: ergonomics, value engineering, redesign.

\section{INTISARI}

Yogyakarta dikenal sebagai kota pelajar, banyak perguruan tinggi negeri maupun swasta. Berdasarkan hal tersebut, mahasiswa berdatangan dari beberapa daerah untuk menempuh pendidikan. Proses pembelajaran dalam perguruan tinggi tidak lepas dari fasilitas yang menunjang kegiatan belajar seperti meja belajar dan laptop. Mahasiswa setiap hari menggunakan laptop dalam kurun waktu yang lama. Sebagian besar mahasiswa mengeluhkan meja belajar kurang nyaman saat digunakan selain itu juga menyebabkan mahasiswa lebih cepat lelah. Kelelahan yang dirasakan pada bagian leher,punggung, kaki dan tangan. Maka dari itu perlu dilakukan perancangan ulang meja belajar mahasiswa agar lebih ergonomis. Metode yang digunakan dalam perancangan ulang meja belajar mahasiswa adalah rekayasa nilai. Identifikasi fungsi dilakukan dengan menggunakan diagram FAST. Dari hasil identifikasi kebutuhan dan fungsi perlu dilakukan perbaikan dan perancangan ulang meja belajar mahasiswa. Sehingga dari penelitian ini didapatkan hasil desain meja belajar mahasiswa dengan penambahan part untuk dapat mengatur tinggi dan kemiringan laptop, tempat untuk gelas dan kabel, tinggi meja belajar yang dapat disesuaikan dan juga sandaran untuk kaki. Kemudian ukuran setiap meja disesuaikan dengan ukuran dimensi tubuh antropometri Indonesia, hasil akhir dari penelitian ini ialah desain meja belajar mahasiswa yang lebih ergonomis.

Kata kunci: ergonomi, rekayasa nilai, perancangan ulang.

\section{PENDAHULUAN}

Kota Yogyakarta dikenal sebagai kota pelajar, banyak perguruan tinggi negeri maupun swasta, berdasarkan hal tersebut, mahasiswa berdatangan dari beberapa daerah untuk menempuh pendidikan. Proses pembelajaran dalam perguruan tinggi tidak lepas dari fasilitas yang menunjang kegiatan belajar seperti meja belajar dan laptop.

Laptop merupakan kebutuhan utama dalam proses perkuliahan. Mahasiswa setiap hari menggunakan laptop dalam kurun waktu yang lama,untuk mengerjakan tugas kuliah. Aktivitas mengerjakan tugas tersebut didukung dengan fasilitas meja. Sebagian besar mahasiswa mengeluhkan bahwa fasilitas meja tersebut kurang nyaman saat digunakan. Meja yang kurang nyaman membuat mahasiswa lebih cepat lelah.

Kelelahan yang dirasakan mahasiswa ketika menggunakan meja belajar terletak pada bagian leher dan punggung (Mutmainah \& Sari, M, 2018). Kelelahan tersebut dapat berpengaruh

186 Maya Susiladewi, et al., Perancangan Ulang Meja Belajar Mahasiswa Dengan Menggunakan Metode Rekayasa Nilai Dan Pendekatan Ergonomi 
pada postur tubuh mahasiswa yakni posisi punggung yang membungkuk. Hal tersebut disebabkan oleh meja yang digunakan untuk meletakkan laptop terlalu rendah, sehingga arah pandang mata pada layar laptop cenderung membuat mahasiswa untuk merunduk. Kelelahan bukan hanya dirasakan pada bagian leher dan punggung, tetapi juga dirasakan pada bagian tangan dan kaki. Kelelahan pada tangan disebabkan oleh posisi tangan yang tidak sejajar dengan posisi laptop, sehingga posisi siku mahasiswa menggantung. Kelelahan pada bagian kaki mahasiswa diakibatkan oleh sandaran kaki yang kurang sesuai dengan kebutuhan, bahkan terdapat meja yang tidak memiliki sandaran kaki.

Perancangan (design) adalah kegiatan awal dari suatu rangkaian kegiatan dalam proses pembuatan produk, atau dengan kata lain perancangan adalah kegiatan awal dari usaha merealisasikan suatu produk yang keberadaanya diperlukan oleh masyarakat untuk meringankan hidupnya. Bentuknya yang paling sederhana, hasil rancangan tersebut dapat berupa sebuah sketsa atau gambar sederhana dari produk yang akan dibuat.

Perancangan ulang suatu produk memiliki peran penting dalam mengidentifikasi risiko penyakit yang muncul akibat tidak sesuainya ukuran suatu produk bagi penggunanya (Hernawati, $T$ \& Ramdani, R, 2019). Pada saat merancang suatu produk masih banyak yang kurang memperhatikan aspek ergonomi. Pada tahap ini bertujuan untuk menghasilkan berbagai macam alternatif untuk memenuhi performance product (Ervina, S., et al., 2013). Suatu ide kreatif atau kreativitas seseorang biasanya berperan dalam mendapatkan alternatif yang dibutuhkan (Nofirza, I. $Z$, 2011). Kreativitas adalah kemampuan untuk menentukan hubungan baru, meneropong suatu hal dari sudut pandang atau perspektif baru dari beberapa konsep (Harsokoesomo, H. D, 2004). Penelitian ini bertujuan untuk merancang ulang meja belajar mahasiswa dengan tujuan diperoleh desain meja belajar yang lebih ergonomis.

\section{HASIL DAN PEMBAHASAN}

Pengumpulan data dilakukan dengan cara menyebarkan kuisioner dengan dua tipe yang pertama untuk desain meja belajar yang sudah ada saat ini, hasil kuisioner setelah disebarkan dapat dilihat pada tabel 1. Kuesioner yang kedua adalah desain meja belajar setelah pengembangan mahasiswa dapat memilih jawaban yang paling sesuai, hasil kuisioner setelah disebarkan dapat dilihat pada tabel 2.

Tabel 1. Kuisioner meja belajar yang sudah ada

\begin{tabular}{llcccc}
\hline \multirow{2}{*}{ Keterangan } & \multicolumn{1}{c}{ Elemen Kriteria } & \multicolumn{3}{c}{ Penilaian } \\
\cline { 3 - 6 } Kenyamanan meja & Tidak sesuai data antropometri & 2 & 43 & 15 & - \\
belajar & Tidak terdapat sandaran kaki & 2 & 6 & 41 & 11 \\
& Hanya dapat untuk meletakan & 1 & 8 & 43 & 8 \\
Fungsi pendukung & laptop atau komputer saja & - & 8 & 40 & 12 \\
& Tidak ada tempat fasilitas lain & 1 & 19 & 31 & 9 \\
Warna & Tidak ada space untuk buku & 2 & 14 & 33 & 11 \\
Sistem & Mencolok & 1 & 7 & 39 & 13 \\
Bahan Baku & Tidak dapat dinaik/turunkan & - & 14 & 37 & 9 \\
\hline
\end{tabular}

Tabel 2. Kuisioner meja belajar setelah pengembangan

\begin{tabular}{|c|c|c|c|c|c|}
\hline \multirow{2}{*}{ Keterangan } & \multirow{2}{*}{ Elemen Kriteria } & \multicolumn{4}{|c|}{ Penilaian } \\
\hline & & 4 & 3 & 2 & 1 \\
\hline \multirow{3}{*}{$\begin{array}{l}\text { Kenyamanan meja } \\
\text { belajar }\end{array}$} & Sesuai data antropometri & 18 & 36 & 6 & - \\
\hline & Terdapat sandaran kaki & 19 & 34 & 5 & 2 \\
\hline & Dapat untuk meletakan laptop dan & 11 & 38 & 8 & 3 \\
\hline \multirow[t]{3}{*}{ Fungsi pendukung } & komputer & & & & \\
\hline & Terdapat tempat fasilitas lain & 20 & 33 & 5 & 2 \\
\hline & Ada space untuk buku & 14 & 32 & 11 & 3 \\
\hline Sistem & Dapat dinaik/turunkan & 22 & 23 & 10 & 5 \\
\hline Sistem & Fleksibel & 19 & 34 & 4 & 3 \\
\hline Bahan Baku & $\begin{array}{l}\text { Kayu dikombinasikan dengan } \\
\text { aluminium }\end{array}$ & 12 & 37 & 7 & 4 \\
\hline
\end{tabular}


Dari data yang diperoleh diolah menggunakan uji validitas dan uji reliabilitas untuk memilih elemen kriteria yang terpilih untuk melakukan perancangan ulang. Hasil uji validitas kuesioner meja belajar yang sudah ada saat ini dapat dilihat pada gambar 3 .

Tabel 3. Hasil uji validitas meja belajar mahasiswa yang sudah ada

\begin{tabular}{ccccc}
\hline Korelasi antara & Nilai korelasi & Nilai $r$ tabel & Keterangan & Kesimpulan \\
\hline Item X1 & 0,097 & & $r$ hitung $<r$ tabel & Tidak Valid \\
Item X2 & 0,517 & & $r$ hitung $\geq r$ tabel & Valid \\
Item X3 & 0,479 & $r$ hitung $\geq r$ tabel & Valid \\
Item X4 & 0,622 & & $r$ hitung $\geq r$ tabel & Valid \\
Item X5 & 0,590 & 0,2500 & $r$ hitung $\geq r$ tabel & Valid \\
Item X6 & 0,388 & & $r$ hitung $\geq r$ tabel & Valid \\
Item X7 & 0,515 & & $r$ hitung $\geq r$ tabel & Valid \\
Item X8 & 0,483 & $r$ hitung $\geq r$ tabel & Valid \\
Item X9 & 0,349 & $r$ hitung $\geq r$ tabel & Valid \\
\hline
\end{tabular}

Karena ada 1 item atribut yang tidak valid pada gambar 3, yaitu item 1 maka item tersebut dikeluarkan dan dilakukan uji validitas lagi. Berikut hasil uji validitas yang kedua yang dapat dilihat pada tabel 4.

Tabel 4. Hasil uji validitas kedua meja belajar mahasiswa yang sudah ada

\begin{tabular}{ccccc}
\hline Korelasi antara & Nilai korelasi & Nilai $r$ tabel & Keterangan & Kesimpulan \\
\hline Item $X 2$ & 0,517 & & $r$ hitung $\geq r$ tabel & Valid \\
Item $X 3$ & 0,479 & & $r$ hitung $\geq r$ tabel & Valid \\
Item $X 4$ & 0,622 & & $r$ hitung $\geq r$ tabel & Valid \\
Item $X 5$ & 0,590 & 0,2500 & $r$ hitung $\geq r$ tabel & Valid \\
Item $X 6$ & 0,388 & & $r$ hitung $\geq r$ tabel & Valid \\
Item $X 7$ & 0,515 & & $r$ hitung $\geq r$ tabel & Valid \\
Item $\times 8$ & 0,483 & & $r$ hitung $\geq r$ tabel & Valid \\
Item $X 9$ & 0,349 & $r$ hitung $\geq r$ tabel & Valid \\
\hline
\end{tabular}

Dari hasil uji validitas kedua, seluruh item atribut sudah valid. Sehingga bisa dilanjutkan untuk tahap uji reliabilitas. Selain uji validitas pada meja belajar mahasiswa yang sudah ada, dilakukan uji validitas juga pada hasil kuisioner meja belajar mahasiswa setelah pengembangan. Pada tabel 5 disampaikan hasil uji validitas pada kuisioner meja belajar mahasiswa setelah pengembangan:

Tabel 5. Hasil uji validitas meja belajar mahasiswa sesudah pengembangan

\begin{tabular}{ccccc}
\hline Korelasi antara & Nilai korelasi & Nilai $r$ tabel & Keterangan & Kesimpulan \\
\hline Item $X 1$ & 0,469 & & $r$ hitung $\geq r$ tabel & Valid \\
Item $X 2$ & 0,861 & & $r$ hitung $\geq r$ tabel & Valid \\
Item $X 3$ & 0,707 & & $r$ hitung $\geq r$ tabel & Valid \\
Item $X 4$ & 0,784 & 0,2500 & $r$ hitung $\geq r$ tabel & Valid \\
Item $X 5$ & 0,841 & $r$ hitung $\geq r$ tabel & Valid \\
Item $X 6$ & 0,769 & & $r$ hitung $\geq r$ tabel & Valid \\
Item $X 7$ & 0,862 & & $r$ hitung $\geq r$ tabel & Valid \\
Item $\times 8$ & 0,508 & $r$ hitung $\geq r$ tabel & Valid \\
\hline
\end{tabular}

Dari data yang diperoleh seluruh item valid, maka dapat dilakukan perhitungan tahap berikutnya yakni uji reliabilitas. Pada tabel 6 dapat dilihat hasil uji reliabilitas untuk hasil kuesioner meja belajar mahaiswa yang sudah ada dan setelah pengembangan:

Tabel 6. Hasil Uji Reliabilitas

\begin{tabular}{llcc}
\hline No & \multicolumn{1}{c}{ Variabel } & Alpha & Kesimpulan \\
\hline 1. & Elemen kriteria meja belajar mahasiswa yang sudah ada & 0,514 & Reliabel \\
2. & $\begin{array}{l}\text { Elemen kriteria meja belajar mahasiswa sesudah } \\
\text { pengembangan }\end{array}$ & 0,873 & Reliabel \\
\hline
\end{tabular}

188 Maya Susiladewi, et al., Perancangan Ulang Meja Belajar Mahasiswa Dengan Menggunakan Metode Rekayasa Nilai Dan Pendekatan Ergonomi 
Kemudian dari hasil uji validitas dan uji reliabilitas dari masing-masing kuisioner, dicari nilai rata-rata, nilai kontribusi dan rangking dari setiap elemen sehingga diperoleh matrik keputusan pada tabel 7 sebagai berikut,

Tabel 7. Matrik Keputusan

\begin{tabular}{|c|c|c|c|c|c|c|c|}
\hline \multicolumn{2}{|c|}{ Perancangan } & Awal & Bobot & Performasi & Pengembangan & Bobot & Performasi \\
\hline \multirow{3}{*}{ Kenyamanan } & 1 & 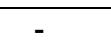 & 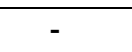 & 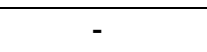 & 3,32 & 0,13 & 0,43 \\
\hline & 2 & 2,05 & 0,11 & 0,22 & 3,27 & 0,13 & 0,42 \\
\hline & 3 & 2,10 & 0,12 & 0,25 & 3,05 & 0,12 & 0,36 \\
\hline \multirow{2}{*}{ Sistem } & 4 & 2 & 0,11 & 0,22 & 2,60 & 0,10 & 0,26 \\
\hline & 5 & 2,27 & 0,13 & 0,29 & 3,05 & 0,12 & 0,36 \\
\hline \multirow{2}{*}{ Fasilitas } & 6 & 2,18 & 0,12 & 0,26 & 3,13 & 0,12 & 0,37 \\
\hline & 7 & 2 & 0,11 & 0,22 & 3,25 & 0,13 & 0,42 \\
\hline Warna & 8 & 2,15 & 0,12 & 0,25 & - & & - \\
\hline Bahan Baku & 9 & 2,65 & 0,15 & 0,34 & 3,03 & 0,12 & 0,36 \\
\hline
\end{tabular}

Dari tabel 7 dapat dilihat perlu dilakukan perancangan ulang meja belajar dengan beberapa elemen kriteria terpilih seperti berikut :

a. Kenyamanan, meja dibuat dengan ukuran data antropometri dan meja belajar terdapat sandaran untuk kaki.

b. Sistem, meja belajar memiliki fungsi dapat digunakan untuk laptop dan komputer, fleksibel, dan dapat dinaik/turunkan.

c. Fasilitas, meja belajar terdapat tempat untuk kabel dan meletakkan gelas, dan meja belajar terdapat sisi untuk meletakkan buku.

d. Warna, meja belajar dibuat dengan warna yang mencolok

e. Bahan Baku, meja belajar dibuat dengan kayu yang dikombinasikan dengan alumunium.

Setelah didapatkan elemen kriteria terpilih untuk desain perancangan ulang meja belajar, diperlukan data antropometri untuk ukuran meja belajar. Data antropometri diperoleh dari data antropometri Perhimpunan Ergonomi Indonesia (PEI), dari data antropometri tersebut dipilih beberapa dimensi tubuh yang sesuai untuk diolah menjadi ukuran meja belajar mahasiswa yang akan dirancang. Berikut beberapa ukuran meja belajar dari beberapa dimensi tubuh yang digunakan:

a. Tinggi meja maksimal menggunakan data dimensi tinggi siku berdiri dengan persentil $50^{\text {th }}$ yaitu 102,76 atau $103 \mathrm{~cm}$. Menggunakan persentil $50^{\text {th }}$ agar mahasiswa dengan tinggi diatas maupun dibawah rata-rata tetap nyaman saat menggunakan meja belajar. Menentukan tinggi meja menggunakan dimensi tubuh tinggi popliteal dijumlahkan dengan tinggi siku posisi duduk dan penambahan allowance. Tinggi politeal ialah $42 \mathrm{~cm}$ dan tinggi siku dalam posisi duduk $28 \mathrm{~cm}$, dengan allowance $5 \mathrm{~cm}$. Kemudian menggunakan persentil $50^{\text {th }}$ agar untuk mahasiswa dengan tinggi di bawah rata-rata tidak terlalu tinggi saat menggunakan meja. Maka dari itu tinggi meja belajar ialah $75 \mathrm{~cm}$.

b. Tinggi pandangan mata yang dimaksud ialah untuk menentukan tinggi maksimal part untuk meletaka laptop. Dimensi tubuh yang digunakan ialah tinggi mata dalam posisi duduk, yaitu 72,97 atau $73 \mathrm{~cm}$.

c. Lebar dan panjang meja didesain dengan ukuran sesuai kebutuhan. Pada desain meja belajar setelah pengembangan dapat digunakan untuk meletakkan laptop dan buku. Ada tempat khusus untuk tempat minu, kabel dan mouse. Maka lebar meja yang dibuat ialah 40 $\mathrm{cm}$ dan untuk panjang meja yang sesuai ialah $75 \mathrm{~cm}$.

d. Ukuran lebar dan panjang untuk alas laptop menggunakan ukuran standart laptop sampai 15 inch. Sehingga untuk lebar alas ialah $25 \mathrm{~cm}$ dan panjang $40 \mathrm{~cm}$.

e. Lebar space/ sisi meletakan buku dan mouse dengan desain meja setelah pengembangan diberikan fasilitas untuk sisi meletakan buku atau untuk menulis dengan ukuran $30 \mathrm{~cm}$ dan ada tempat mouse yang fleksibel dapat ditarik/dimasukkan dengan ukuran lebar yakni 20 $\mathrm{cm}$.

f. Lebar sandaran kaki menggunakan dimensi tubuh panjang kaki yaitu 23,92 atau $24 \mathrm{~cm}$. 
Berikut desain meja belajar mahasiswa setelah dilakukan pengembangan adapun hasilnya dapat dilihat pada gambar 1 ukuran meja belajar tampak depan, ukuran meja belajar tampat samping pada gambar 2, gambar 3 ukuran meja tampak atas. Desain secara 3 dimensi meja belajar tampak depan dapat dilihat pada gambar 4, sedang pada gambar 5 berupa desain 3 dimensi meja belajar tampak belakang.

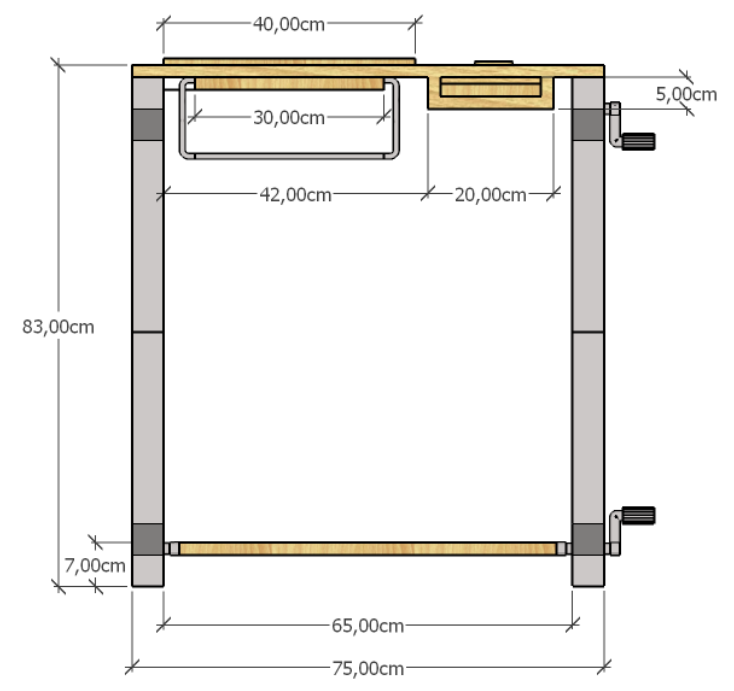

Gambar 1. Ukuran meja belajar tampak depan

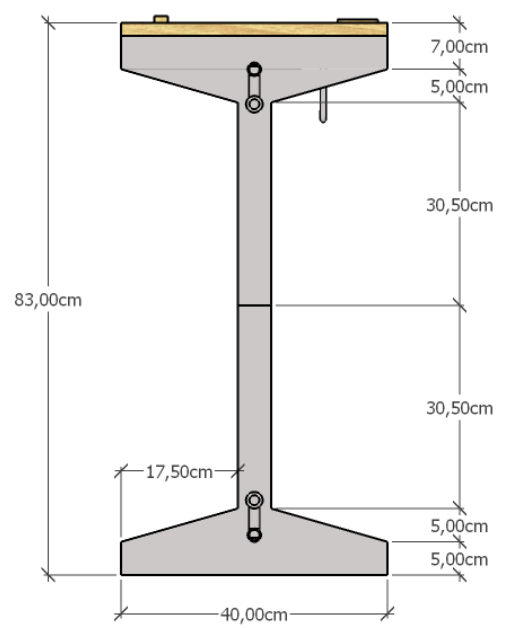

Gambar 2. Ukuran meja belajar tampak samping

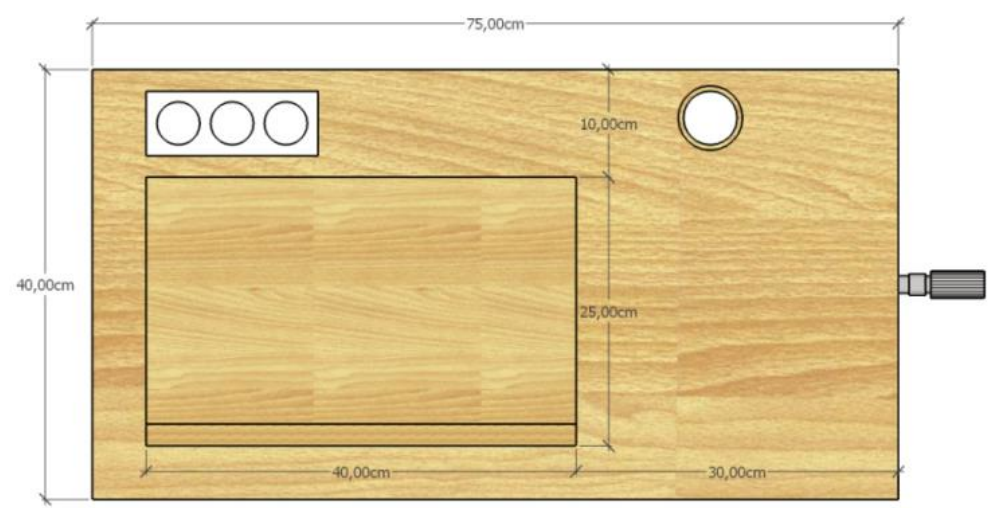

Gambar 3. Ukuran meja belajar tampak atas

190 Maya Susiladewi, et al., Perancangan Ulang Meja Belajar Mahasiswa Dengan Menggunakan Metode Rekayasa Nilai Dan Pendekatan Ergonomi 


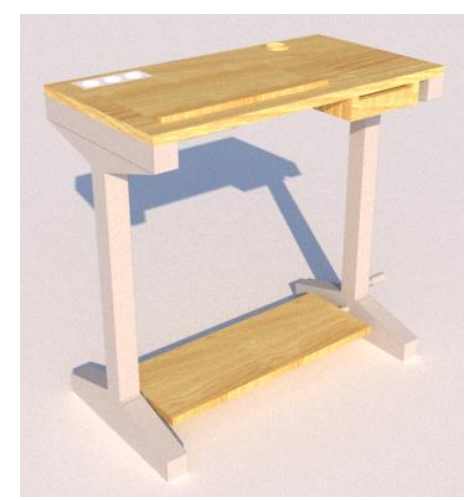

Gambar 4. Desain 3 dimensi meja belajar tampak depan

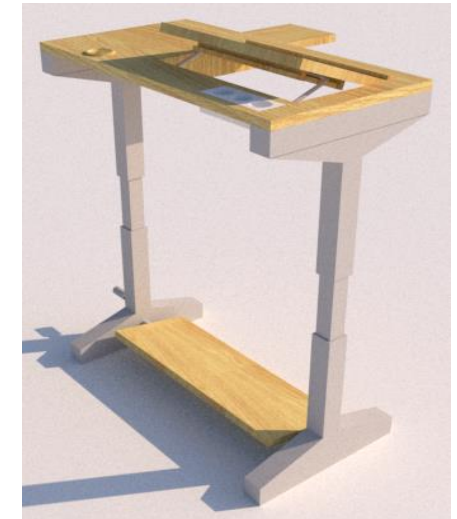

Gambar 5 Desain 3 dimensi meja belajar tampak belakang

\section{KESIMPULAN}

Dari data penelitian didapatkan atribut yang dibutuhkan untuk melakukan pengembangan menggunakan metode FAST pada produk meja belajar mahasiswa yaitu kenyamanan, sistem, fasilitas, warna dan bahan baku. Diperoleh desain meja belajar mahasiswa menjadi lebih ergonomis, tinggi meja belajar $75 \mathrm{~cm}$ dengan lebar meja $40 \mathrm{~cm}$ dan untuk panjang meja $75 \mathrm{~cm}$ serta lebar sandaran kaki $24 \mathrm{~cm}$.

\section{DAFTAR PUSTAKA}

Andriani, D. P., Choiri, M., \& Priharseno, D, 2017, Aplikasi Quality Function Deployment untuk Redesign Kontainer Penyimpanan Pada Industri Kemasan Kaleng, Jurnal Teknik Industri, 18 (2), 176-190.

Andrianyansyah, A. A., Safi'I, Imam., \& Santoso, H. B, 2020, Perancangan Pengembangan Produk Kursi Tunggu Multifungsi dengan Metode Rekayasa Nilai (Value Engineering), Jurnal Teknik Industri, 2 (2), 118-127.

Anwar, Syaiful, 2000, Pembuatan Meja Komputer Pendekatan Ergonomi dengan Metode Function Analysis System Technique, Skripsi, Institut Sains dan Teknologi AKPRIND Yogyakarta.

Bruno, Fabrizo., Califano, Rosaria., Greco, Ruben., Ricco, Giuseppe., Vallone, Mariarisaria., \& Valter, Narcisa, 2016, Virtual Ergonomic Analysis and Redesign of a Dentist's Workcyle, Journal of Engineering and Aplied Sciences.

Ervina, S. U., Nandiroh, S., \& Munawir, H, 2013, Analisa Pengembangan dan Perancangan Desain Produk Kursi Gajah Garuda Menggunakan Metode Rekayasa Nilai dan Analytical Hierarchy Process (AHP), Jurnal Teknik Inudstri, 2 (1), 22-35.

Harsokoesomo, H. D, 2004, Pengantar Perancangan Teknik, edisi ke 2, Institut Teknologi Bandung.

Hernawati, T \& Ramdani, R, 2019, Desain Kursi Santai Multifungsi Ergonomis dengan Menggunakan Pendekatan Antropometri,. Jurnal Industrial Manufacturing, 4 (1), 45-54.

Nofirza, I. Z, 2011, Perancangan Alat Belajar dan Bermain yang Ergonomis di Taman Kanak-kanak Islam Permata Selat Panjang, Jurnal IImiah Teknik Industri, 10 (1), 48-58. 